\title{
O De anima de Aristóteles e a CONCEPÇÁo das FACULDADES DA ALMA NO KITÁB AL-NAFS (Livro da Alma, De anima) de IbN Sina (Avicena)
}

RESUMO: Este artigo apresenta uma comparação conceitual entre a obra De anima, de Aristóteles, e a concepção das faculdades da alma no Kitáb al-Nafs - edição árabe - (Livro da Alma, De anima), de Ibn Sina (Avicena), com o intuito de mostrar similitudes e influências de Aristóteles sobre o pensamento de Ibn Sina, nessa temática. Destaca, ainda, como e a época em que o estagirita foi recebido em terras do Islã, indicando o seu primeiro receptor, o filósofo Al-Kindi, assim como, de modo pormenorizado, uma comparação sobre a definição de alma dada pelos dois filósofos, e as três espécies de alma, com ênfase para o conceito de alma racional. Apresenta, também, a estrutura de cada uma das obras.

PALAVRAS-CHAVE: Aristóteles. Ibn Sina. Avicena. alma. faculdades da alma. filosofia islâmica.

\section{INTRODUÇÁO}

A filosofia grega teve significativa receptividade no mundo árabe e, particularmente, no mundo muçulmano. Tal fato ocorreu a partir do século VIII, com o interesse pela tradução que os árabes dedicaram às obras de alguns dos mais importantes filósofos da Grécia Antiga. Platão e Aristóteles figuram entre os que mais influenciaram a filosofia elaborada em terras do Islá.

Ibn Sina ou Avicena (980-1037), como é conhecido no mundo latino, foi o pensador que dedicou grande interesse à filosofia de Aristóteles. Entretanto, se, por um lado, Ibn Sina foi muito influenciado pela filosofia do estagirita, por outro, não é possível afirmar que foi seu fiel seguidor. Discordou e modificou muitos aspectos da filosofia do Primeiro Mestre (al-Mu 'alím al-awal), como Aristóteles ficou conhecido entre os árabes.

\footnotetext{
${ }^{1}$ Professor de História da Filosofia Medieval Árabe na Universidade Federal de São Paulo (UNIFESP),
} campus Guarulhos. 
Não há dúvida de que Aristóteles, o Aristútálís dos árabes, teve enorme hospitalidade filosófica no mundo islâmico, que conheceu praticamente todas as suas obras, que, num primeiro momento, só foi superada pelo interesse dedicado à hermenêutica alcorânica pelos muçulmanos. O De anima de Aristóteles - os problemas da alma, sua natureza e sua existência - foram muito estudados pelos filósofos muçulmanos, em função das implicaçóes religiosas, ou seja, dos ditos alcorânicos, dessas noçóes.

Al-Kindi (796-873) foi o introdutor da filosofia do estagirita entre os árabes; al-Farabi (872-950) ampliou consideravelmente o conhecimento a respeito da filosofia aristotélica, e Ibn Sina foi o "O Grande Mestre" (Al-Shaikh, al-Raís) dessa situação. Pode-se dizer que os muçulmanos foram, de fato, também herdeiros de Aristóteles.

No elenco das obras de Aristóteles traduzidas ao árabe, entre os séculos IX e X, encontra-se o De anima, livro que aqui nos interessa.

Tanto o De anima de Aristóteles como o de Kitáb al-Nafs (Livro da Alma), conhecido como o De anima de Avicena, estâo no conjunto de conhecimentos que fazem parte da física - como ciência natural - , na qual o homem está inserido; e não na metafísica. Em ambos, a alma é um tema da psicologia concebida em termos de faculdades. Aqui, temos uma primeira e importante coincidência.

Praticamente, as duas obras têm a mesma estrutura, a saber: apresentam o conceito de alma em geral; alma vegetal, alma sensível (animais) e alma intelectiva (humana).

\section{A DEFINIÇÃo DA ALMA² SEGUNdo IbN SinA}

\section{Avicena afirma:}

[...] dizemos: certamente observamos corpos que sentem e se movem voluntariamente, mas (também) observamos corpos que se nutrem, crescem e engendram (outros corpos) semelhantes. E (estes corpos) não são isto por sua corporeidade; resta, então, que há para isto, em suas essências, princípios que não são a sua corporeidade. E a coisa da qual procedem estas ações e (também) geralmente todo princípio da procedência destas açóes, que de um modo único não prescinde da vontade, chamamos alma. Este termo é nome para esta coisa não porque é substância, mas por um certo aspecto que tem, ou seja, pelo aspecto que é princípio para estas açóes. (De anima - Kitáb al-Nafs - capítulo I, P.9, linhas 1-8).

\footnotetext{
2 Utilizo aqui o livro em árabe da Editions du Patrimoine Árabe et Islamique - Paris - Ediçăo da Enterprise Universitaire d'Etude et Publication, Beirut, 1988. Psychologie D'lbn Sina (Avicenne) D'après son Ouvre Al-Shifa'.
} 
A alma é, também, perfeição primeira de um corpo, o qual deve ser entendido como corpo jinsí (como gênero), e não material.

Com relaçáo à substancialidade da alma, o nosso filósofo enfatiza: “[...] a presença da alma num corpo não é como a presença do acidente ${ }^{3}$ num sujeito; entáo, certamente, a alma é substância porque é forma que não está num sujeito" (Cap. III, P. 30, linhas 6 e 7).

E ainda: "[...] é necessário que ela (a alma) em si mesma seja, de modo algum, em um sujeito - e já soubeste o que é o sujeito ${ }^{4}$ - E se toda alma existe não num sujeito, entáo, toda alma é uma substância” (P. 13, linha 21 e P.14).

\section{A DEFiniçáo da ALMA SEgundo ARISTóteles}

[...] ficam explicadas as doutrinas transmitidas por nossos predecessores a respeito da alma. Voltemos, pois, de novo desde o início e tentemos definir que é a alma e qual poderia ser sua definição mais geral. (De anima, II, 412, 5).

Costumamos dizer que um dos gêneros dos entes é a entidade e que esta pode ser entendida, em primeiro lugar, como matéria - aquilo que por si não é algo determinado -; em segundo lugar, como estrutura e forma, em virtude da qual pode dizer-se já da matéria que é algo determinado; e, em terceiro lugar, como o composto de uma e outra. Ademais, a matéria é potência enquanto a forma é entelequia ${ }^{5}$. Esta, por sua vez, pode entender-se de duas maneiras, segundo seja como a ciência e como o ato de teorizar.

Por outra parte, e ao que parece, entidades são de maneira primordial os corpos e, entre eles, os corpos naturais: estes são os principais entre todos os demais. Entre os corpos naturais, há os que têm vida e os que náo a têm; e costumamos chamar vida à autoalimentação, ao crescimento e ao envelhecimento, donde resulta que todo corpo natural que participar da vida é entidade, porém, entidade no sentido de entidade composta. E, posto que se trate de um corpo de tal tipo - a saber, que tem vida - não é possível que o corpo seja alma: e é que o corpo não é das coisas que se dizem de um sujeito; antes, ao contrário, realiza a função de sujeito e matéria - logo, a alma é necessariamente entidade, enquanto forma

\footnotetext{
3 Aqui, Ibn Sina quer dizer que a alma não veio ao corpo por acidente.

${ }^{4}$ Sujeito no sentido geral de receptáculo, por exemplo, da substância e do acidente.

${ }^{5}$ A título de recordação, entelequia foi a expressáo criada por Aristóteles para conceituar o ato perfeito, a realizaçáo acabada de uma potência (vide Met., IX, 8, 1050 a 23).
} 
específica de um corpo natural que em potência tem vida. Portanto, a entidade é entelequia, logo a alma é entelequia de tal corpo (De anima 412, 10-20)

Aristóteles continua: “[...] portanto, se cabe enunciar algo em geral a respeito de toda classe de alma, haveria que dizer que é entelequia primeira de um corpo natural organizado" (De anima 214b, 5).

Como se pode constatar, Ibn Sina afirma, com Aristóteles, que a alma é forma e perfeição de um corpo. No entanto, diverge do estagirita, ao afirmar que ela é uma substância, e para isso dá o exemplo que ficou conhecido como $a$ alegoria do homem voador, muito célebre entre os escolásticos medievais. Veremos isso mais adiante.

\section{As FACULDADES DA ALMA}

Tal qual Aristóteles, Ibn Sina sustenta que há três espécies de alma, a saber: alma vegetal, alma animal e alma humana.

Vejamos a seguinte exposição de Ibn Sina:

[...] dizemos agora que a primeira das divisōes das açôes da alma são três: aquelas nas quais se incluem, se associam, o animal e o vegetal, tais como a nutrição, o crescimento e a geração; são ações nas quais estão incluídos os animais ou a maior parte deles - nas quais não há participaçáo dos vegetais, tais como a sensação, a imaginação e o movimento voluntário; e as açóes próprias dos seres humanos, como, por exemplo, a concepçáo dos inteligíveis, a invençáo das artes, o discernimento dos seres engendrados e a distinção entre o belo e o feio. (Kitáb al-Nafs- P.40. linhas 1-10).

Por outro lado, Aristóteles afirma:

[...] chamávamos potências às faculdades nutritiva, sensitiva, desiderativa, motora e discursiva. Nas plantas se dá somente a faculdade nutritiva, enquanto que nos outros viventes se dá não apenas esta, mas também a sensitiva. Por outra parte, ao dar-se a sensitiva se dá também (neles), a desiderativa. $\mathrm{O}$ apetite, os impulsos e a vontade são três classes de desejos. Entretanto, todos os animais possuem ao menos uma das sensaçôes; o tato. [...] há animais que além destas faculdades lhes corresponde também a do movimento local; a outros, lhes corresponde, ademais, a faculdade discursiva e o intelecto: este é o caso dos homens e de qualquer outro ser semelhante ou mais excelso, supondo que o haja. (De anima, 414a, 30 ; 414b). 
Note-se que, nos dois autores, estão presentes as três: a intelectivo-racional, que corresponde especificamente à alma humana, a sensitiva, que corresponde aos animais, e a nutritiva, aos vegetais.

\section{A ALMa VEgetal - CONCEPÇáo de IbN Sina}

A alma vegetal é a perfeição primeira de um corpo natural munido de órgãos pelo aspecto de que cresce, gera e se nutre (Kitáb al- Nafs, p. 40, linhas 2-4).

A alma vegetal possui três faculdades. A faculdade nutritiva, a faculdade do crescimento e a faculdade da geração.

Percebe-se aqui uma influência do De anima de Aristóteles, tanto no conteúdo como na estrutura de apresentação.

\section{As FACULDADES ANIMAIS}

A alma animal possui duas faculdades: a motora e a da percepçấo (P. 41, linhas 1-2.). E ela tem duas ramificaçôes: um ramo que se chama faculdade concupiscível, sendo uma faculdade que excita ao movimento pelo qual ela aproxima as coisas estimadas necessárias ou úteis, buscando o prazer, enquanto o outro ramo se chama (faculdade) irascível, sendo uma faculdade que excita ao movimento pelo qual ela repele a coisa que é estimada como prejudicial ou corruptora, procurando a vitória (P. 41, linhas 12-14). Quanto à faculdade motora, enquanto age, ela é uma faculdade excitada nos nervos e nos músculos (P. 42, linha 1).

No que concerne à faculdade que percebe (de percepção), divide-se em duas partes: uma delas (é a faculdade) que percebe de fora; a outra (é a faculdade) que percebe de dentro. (p. 42, linhas 4-5).

O segundo ramo pertence às faculdades de percepção, ou seja, dos sentidos internos, representados pela fantasia (ou sentido comum), imaginação ou formativa; imaginativa (no animal) e cogitativa (no homem) e estimativa; a que conserva e se lembra.

Das faculdades perceptivas internas do animal, uma faculdade é a fantasia, que é o sentido comum; é uma faculdade estabelecida no primeiro ventrículo do cérebro que recebe por si mesma todas as formas impressas nos cinco sentidos que chegam a ele (ao ventrículo). (p. 44, linhas 15-16). 
E a faculdade, que se chama imaginativa em relação à alma animal e cogitativa em relação à alma humana, é uma faculdade estabelecida no ventrículo médio do cérebro junto ao verme ${ }^{6}$; ela tem a prioridade de compor certas coisas que estão na imaginação com outras e (também) de separar outras de acordo com a vontade (P. 45, linhas 11-13).

E a faculdade estimativa, que é a faculdade estabelecida na extremidade do ventrículo médio e percebe as intenções não sensíveis existentes nas coisas sensíveis particulares (P.45, linhas 14-16)

E a faculdade que conserva e se lembra, que é uma faculdade estabelecida no ventrículo posterior do cérebro. Ela conserva o que a faculdade estimativa percebeu das intençōes não sensíveis nas coisas sensíveis particulares (P. 46, linhas 2-4).

Não se deve estranhar as minúcias de Ibn Sina, ao expor detalhadamente a localização as faculdades da alma (nervos e músculos etc.) pois ele foi médico e entendia muito de anatomia, algo que não ocorreu com Aristóteles.

\section{A ALMA RACIONAL HUMANA}

Ibn Sina salienta que, quanto à alma racional humana, suas faculdades dividem-se em faculdade que age e faculdade que conhece, sendo que cada uma das duas faculdades se chama inteligência por homonímia ou equivocidade.

Há também uma diferença importante a ser considerada pelo exposto acima: Ibn Sina concebe o cérebro como o órgão que agrega as sensaçóes, enquanto, para Aristóteles, esta é uma função do coração.

Vale lembrar, ainda, que em Aristóteles a faculdade que age é o intelecto prático e a faculdade que conhece é o intelecto teórico.

Vejamos o que ressalta Aristóteles:

[...] recapitulando agora a doutrina que expusemos a respeito da alma, dizemos uma vez mais que a alma é em certo modo todos os entes já que os entes são ou inteligíveis ou sensíveis e o conhecimento intelectual se identifica em certo modo com o inteligível, assim como a sensaçáo com o sensível. Vejamos de que modo isto é assim.

O conhecimento intelectual e a sensação se dividem de acordo com seus objetos, isto é, enquanto estáo em potência têm como correlato seus objetos em potência, e enquanto estão em ato, seus objetos em ato. Por sua vez, as faculdades sensíveis e intelectuais da alma são em potência seus objetos; o inteligível e o sensível, respectivamente. Porém, estes hão de ser necessariamente ou as coisas mesmas,

\footnotetext{
${ }^{6}$ Verme: é uma referência ao verme do cérebro, que é o lóbulo médio do cérebro entre os hemisférios.
} 
ou suas formas. E, por certo, não são as coisas mesmas; o que está na alma não é a pedra, mas a forma desta. Donde resulta que a alma é comparável à mão, já que a mão é instrumento de instrumentos e o intelecto é forma de formas assim como o sentido é forma das qualidades sensíveis. E posto que, ao que parece, não existe coisa alguma separada e fora das magnitudes sensíveis, os objetos inteligíveis tanto os denominados abstraçóes como todos aqueles que constituem estados e afecçóes das coisas sensíveis - encontram-se nas formas sensíveis. Daqui que, carecendo de sensação, não seria possível nem apreender nem compreender. Daí também que quando se contempla intelectualmente, se contempla de uma vez e necessariamente alguma imagem: é que as imagens são como sensaçôes, porém, sem matéria. A imaginação é, ademais, algo distinto da afirmaçáo e da negação, já que a verdade e a falsidade consistem numa composição de conceitos. Quanto aos conceitos primeiros ${ }^{7}$, em que se distinguem das imagens? Não caberia dizer que nem estes nem os demais conceitos são imagens, se bem nunca se dão sem imagens. (De anima VIII, 20, 25; 432 a , 5-10).

\section{Faculdade imaginativa:}

[...] se a imaginação é aquilo em virtude do qual costumamos dizer que se origina em nós uma imagem - exclusão feita de todo uso metafórico da palavra - há de ser uma daquelas potências ou disposiçóes por meio das quais discernimos e nos situamos ou na verdade ou no erro. E estas são sentido, opinião, intelecto e ciências. (De anima III, 428 a).

É interessante observar que há um longo discurso no De anima sobre essa questão, que não é o nosso objeto aqui.

O mais interessante a ser notado, em termos de comparaçáo, é quanto ao estatuto ontológico da alma. Ibn Sina afirma, como Aristóteles, que a alma é forma e perfeiçáo de um corpo. Entretanto, diferencia-se do estagirita, ao entender que ela é uma substância e, para isso, dá exemplo que ficou conhecido como $a$ alegoria do homem voador. Esta alegoria é a seguinte:

[...] observe a ti mesmo e reflita. Quando estás em boa saúde, ou melhor, quando está em estado normal, tal que te permite compreender propriamente as questóes; esqueces por um momento tua própria existência, e cessas um só instante de afirmar teu próprio ser? Ninguém que observa cuidadosamente responderia negativamente, e inclusive no homem que dorme, ou no intoxicado pelo álcool, não está ausente da mente a consciência de seu ser interno, ainda que não possa dar conta do que o circunda. E se te imaginas a ti mesmo como havendo sido, desde o momento em que nasceste, uma pessoa de mente e

${ }^{7}$ Com relação ao termo primeiros, não há unanimidade a respeito dos conceitos chamados por Aristóteles de primeiros. Para alguns, trata-se dos conteúdos primários e fundamentais do pensamento; não seriam abstraçôes a partir da experiência sensível. Para outros, é uma referência aos conceitos menos abstratos, mais próximos das imagens sensíveis. 
disposiçōes saudáveis, e depois imaginas que estás suspenso no espaço durante um instante, de tal maneira que não vês as partes de teu corpo e teus membros estâo separados para que não possam tocar-se, encontrarás que embora ignores o que te circunda, te dás conta do fato de que existes. Por meio de que percebes a ti mesmo em tal estado, ou antes ou depois dele (deste estado). E quem é que percebe em ti? É por meio de teus sentidos, ou tua mente ou alguma outra faculdade ademais de teus sentidos e que se corresponde com elas?. Se é por meio de tua mente e alguma faculdade além de teus sentidos, o fazes com ajuda de um intermediário ou diretamente? Não necessitas de um intermediário durante esse momento, nem este existe. Portanto, te percebes a ti mesmo sem necessitar de nenhuma outra faculdade ou meio, e a percepçáo tem lugar por meio de teus sentidos ou de algum sentido interno. Vamos um pouco além. Deduzes de tudo isto que o percebido de ti é o que a vista percebe de tua carne? Isto não pode ser, porque si perdes esta carne e tivesses outra, serias o que és. Ou trata-se daquilo que o sentido do tato percebe? Isto tampouco pode ser, salvo para os membros como o coraçáo ou o cérebro. Porque, como poderia ser que o que percebes são tais membros, tendo em vista que de sua existência apenas te inteiras quando se leva a cabo uma dissecção? O que percebes não é um conjunto de coisas enquanto conjunto [...] Assim, o que percebes é algo diferente de todas as coisas que não percebes enquanto percebes te percebes a ti mesmo, e que a ti não te parecem necessárias para fazer de ti o que és. Assim, o tu mesmo que percebes não pertence, de nenhuma maneira, à ordem das coisas que tu percebes mediante os sentidos ou o que se parece aos sentidos. (Isharát p. 120).

\section{E Ibn Sina prossegue:}

[...] talvez digas que, na realidade, eu provo (a existência de) meu próprio ser com ajuda de minha açâa. Neste caso, terás que provar o ato ou o movimento ou alguma outra coisa. . A suposição de que estás suspenso no espaço implica que te isolamos de tudo isso. Mas, como princípio geral, se provas teu ato como sendo absolutamente um ato, tens que provar por isto mesmo, não de maneira particular, mas que há, absolutamente, um agente, que é, definitivamente, teu próprio ser. Se provas que é um ato teu e não provas teu ser mesmo por meio dele e, ademais, se é parte do que se entende por teu ato enquanto ato teu, estará provado no entendimento, antes que ele ou, pelo menos, com ele, mas náo por meio dele. Tua "mesmidade" não se prova assim, por meio dele. (Isharát, P.120).

Com esse argumento, Ibn Sina quer mostrar a não dependência da alma do corpo para existir, e acentuar o conceito da mesma como substância. A definição de Aristóteles da alma como entelequia primeira de um corpo natural organizado ou, ainda, como forma de um corpo, não implica certeza para garantir que a alma é substância independente do corpo ou não. Se tomarmos as palavras de Ibn Sina, quando dizemos perfeição, ainda náo se conhece com isso se a alma é uma substância ou não é substância, porque o significado de perfeição é a coisa pela 
existência da qual o animal se torna animal em ato e o vegetal, vegetal em ato; e isso não faz conhecer, ainda, que ela seja substância ou não seja substância.

ISKANDAR, Jamil Ibrahim. El De anima de Aristóteles y la concepción de las facultades del alma en el Kitáb al-Nafs (Libro del Alma, De anima) de Ibn Sina (Avicena). Trans/Form/ Ação, Marília, v. 34, n.3, p. 41-50, 2011.

RESUMEN: Este artículo presenta una comparación conceptual entre la obra "De anima” de Aristóteles y la concepción de las facultades del alma en el Kitáb al-Nafs - edición árabe - (libro del Alma, De anima) de Ibn Sina (Avicena), con el propósito de señalar similitudes e influencias de Aristóteles en el pensamiento de Ibn Sina relativos a esta temática. Destaca, también, el modo y la época en el que el Estagirita fue recibido en tierras del Islam y el primer receptor de Aristóteles, el filósofo Al-Kindi, y compara de modo pormenorizado la definición del alma presentada por los dos filósofos y las tres especies del alma, con énfasis en el concepto del alma racional. Presenta, también, la estructura de cada una de las obras.

PALABRAS CLAVES: Aristóteles. Ibn Sina. Avicena. alma. facultades del alma. filosofía islámica.

\section{REFERÊNCIAS}

ARISTÓTELES. Acerca del alma. Introdução, tradução do grego e notas de Tomás Calvo Martinez. Madrid: Gredos, 1994.

IBN SINA (Avicena). Kitáb al-Isharát wa al-Tanbihát (Livro das diretivas e advertências). Qom (Irã): Bústán-e Ketáb, 2008.

. Psychologie D'Ibn Sina (Avicenne) D'après son Ouvre Al-Shifá', edição árabe.

Paris: Editions du Patrimoine Árabe et Islamique, Beirut, 1988.

recebido em: 27.06.2011

aprovado em: 04.10 .2011 